\title{
Erratum to: Study on the mesothelin-specific cytotoxicity against epithelial ovarian cancer with full-length mesothelin cDNA- transduced dendritic cells
}

\author{
Dong-hui Wang ${ }^{1,2} \cdot$ Xiao-hua $\mathrm{Wu}^{1,3} \cdot$ Su-min Qian ${ }^{4} \cdot$ Hai-Rong Yao ${ }^{2}$
}

Published online: 29 May 2015

(c) Springer Science+Business Media New York 2015

Erratum to: Med Oncol (2015) 32:116

DOI 10.1007/s12032-015-0561-7

The corresponding author would like to include an additional affiliation. Her affiliations should read as mentioned below.

The online version of the original article can be found under doi:10.1007/s12032-015-0561-7.

Xiao-hua Wu

wuxiaohua2001@hotmail.com

Dong-hui Wang

czwangdonghui@hotmail.com

Su-min Qian

2273751895@qq.com

Hai-Rong Yao

2824237209@qq.com

1 Teaching and Research Section of Obstetrics and

Gynecology, Hebei Medical University,

Shijiazhuang 050011, China

2 First Department of Gynecology, Cangzhou Central Hospital, Cangzhou 061001, China

3 Department of Gynecology, Bethune International Peace Hospital, Shijiazhuang 050082, China

4 Second Department of Gynecology, Cangzhou Central Hospital, Cangzhou 061001, China 